\title{
Predictive testing of early cervical pre-cancer by detecting human papillomavirus E6/E7 mRNA in cervical cytologies up to high-grade squamous intraepithelial lesions: Diagnostic and prognostic implications
}

\author{
ALINDA D. VARNAI ${ }^{1}$, MAGDOLNA BOLLMANN $^{1}$, AGNES BANKFALVI $^{2}$, \\ NORBERT SPEICH ${ }^{3}$, CHRISTOPH SCHMITT ${ }^{3}$, HARALD GRIEFINGHOLT ${ }^{1}$, \\ KRISZTINA KOVÁCS $^{4}$, CHRISTIANE KLOZORIS ${ }^{1}$ and REINHARD BOLLMANN ${ }^{1}$ \\ ${ }^{1}$ Institute of Pathology, Heilsbachstrasse 15, D-53123 Bonn-Duisdorf; ${ }^{2}$ Institute of Pathology and Neuropathology,
University Clinic of Essen, Hufelandstrasse 55, D-45122, Essen; ${ }^{3}$ IMoGen GmbH, Heilsbachstrasse 17,
D-53123 Bonn-Duisdorf, Germany; ${ }^{4}$ University of Pécs, Medical School, Department of Pathology, Pécs, Hungary
}

Received August 6, 2007; Accepted October 24, 2007

\begin{abstract}
The type-specific persistence of oncogenic human papillomavirus (HPV) is considered to be the true precursor of cervical cancer at which the transcription of the viral oncogenes E6 and E7 is necessary for the malignant transformation and maintenance of the neoplastic state. In the present pilot study, a cohort of 66 women was investigated from a routine officebased screening population who had an index cytological result from normal to high-grade squamous intraepithelial lesions and who were also HPV-DNA positive for at least one of the following high-risk HPV types: HPV 16, 18, 31, 33 and 45 detected by MY09/MY11 consensus and GP5 ${ }^{+} / 6^{+}$ general primers, followed by sequencing. The expression of E6/E7 transcripts from the same HPV types was detected by the PreTect HPV-Proofer. Cervical status was checked 18 months after the mRNA test. The expression of E6/E7 mRNA was found in $58 \%$ of the cases showing a $97 \%$ concordance with the HPV-DNA types and a positive correlation with increasing cytological and histological grade. All HPV-mRNA positive cases were also positive for HPV DNA whereas 25 (38\%) of the HPV-DNA positive cases did not express the respective mRNA. The diagnostic validity of the PreTect assay for detecting histologically-proven prevalent CIN3 lesions were: sensitivity $95 \%$, specificity $55 \%$, positive predictive value (PPV) $81 \%$ and negative predictive value (NPV) $86 \%$. The prognostic power of the PreTect test for predicting cytological disease progression was as follows: $78 \%$ sensitivity, $60 \%$ specificity, $37 \%$ PPV and $90 \%$ NPV. In conclusion, our
\end{abstract}

Correspondence to: Dr Reinhard Bollmann, Institute of Pathology, Heilsbachstrasse 15, D-53123 Bonn-Duisdorf, Germany

E-mail: reinhard@bollmann.com

Key words: human papillomavirus, genotyping, E6/E7 mRNA, cytology, cervical carcinoma results showed that the detection of oncogenic HPV E6/E7 mRNA in cervical smears in a routine screening setting identifies prevalent CIN3 lesions with nearly 100\% sensitivity and has a very high negative predictive value for disease progression during the natural course of HPV infection. Thus, testing for HPV oncogenic activity may be used as a clinically predictive marker to enhance the net effectiveness of screening and enable the prognostication of prevalent cervical lesions.

\section{Introduction}

The human papillomavirus (HPV) is now conclusively identified as a primary cause of cervical cancer (1-3) and HPV testing is becoming an important tool in cytology-based cervical cancer screening. The combination of cytology and HPV detection seems to save additional lives at a reasonable cost compared to the Pap test alone (4). However, despite its causal role in carcinogenesis, most women with HPV do not get cervical cancer, owing to the fact that the majority of HPV infections are transient, especially in younger age groups $(5,6)$. The identification of those HPV-positive women, who are at an increased risk for developing high-grade intraepithelial neoplasia (CIN3) and subsequent invasive carcinoma, is a key issue in risk-adapted screening. However, even the highly sensitive test combination of cytology and high-risk HPV detection cannot assess the biological potential of existing cervical intraepithelial lesions (SIL) and the natural history of minor cytological aberrations (ASCUS) is even more difficult to predict. Therefore, there is a need for rational and biologically relevant combinations of different test modalities, including the detection of HPV-related molecular biomarkers, to enhance the net effectiveness of screening and enable the prognostication of prevalent cervical lesions.

The majority of existing or proposed HPV screening protocols are DNA-based tests providing results on the presence or absence of HPV in general or with regard to specific genotypes in cytological samples. The type-specific persistence of oncogenic HPV is considered to be the true 
precursor of neoplastic progression $(7,8)$, whereas the expression of the E6/E7 oncogenes is necessary for the malignant transformation and maintenance of the neoplastic state $(9,10)$. Therefore, the detection of the E6/E7 mRNA of the respective HPV genotypes may serve as a better prognostic test than mere DNA detection for the development of highgrade squamous intraepithelial lesions (HSIL) and invasive carcinoma (11-13).

The aim of the present pilot study was to assess the diagnostic and prognostic validity of detection of the oncogene E6 and E7 mRNA expression from HPV types 16, 18, 31, 33 and 45 using the PreTect HPV-Proofer test in women with index cervical cytologies up to HSIL and known type-specific HPV DNA status from a routine screening population. The results were compared to those of type-specific HPV DNA assays, cytology and histology at baseline, if available. Cervical status was checked 18 months after the mRNA test by liquid-based cytology and HPV DNA genotyping.

\section{Materials and methods}

Patients and samples. A cohort of 66 women was included in this study from a routine office-based screening population from the Bonn region in West Germany who performed their annual cervical screening in different referral gynaecological practices from December 2005 to March 2006. Patients were selected on the basis of having an index cytological result from normal to high-grade squamous intraepithelial lesions at baseline. These patients were HPV-DNA positive for at least one of the 5 high-risk HPV types (HPV 16, 18, 31, 33 and 45), which are included in the PreTect HPV-Proofer mRNA assay (Norchip AS, Norway). Three HPV-DNA negative cases were also investigated for control purposes, whereas overt carcinomas were not included in the study.

Exfoliated epithelial cells were taken by a cervical sampler brush, rinsed directly into a methanol-based fixative solution in a PreserveCyt vial and sent to the Institute of Pathology in Bonn-Duisdorf for routine reporting and ancillary testing, if appropriate. Biopsy was performed in seven women, 26 received conisation and the rest of the patients $(n=33)$ did not get surgical treatment at all. Cervical status was monitored by repeat cytological assessment 18 months after the mRNA test. Six women were unable to be followed up. A second HPV DNA genotyping was performed in 31 out of 33 non-treated patients.

\section{Procedures}

Cytology. Thin-layer preparations were made using the ThinPrep 2000 processor (ThinPrep, Cytyc Corp., USA). Cytological diagnoses and specimen adequacy were classified according to the modified Munich II Cytological classification (standard in Germany) (14) and converted into the Bethesda 2001 terminology as follows: Pap I (unsuspicious) and Pap II (inflammatory) lesions were considered to be negative for intraepithelial lesion or malignancy (no-ASC); Pap IIw [(w = wiederholen/repeat): not an official class in the Munich II classification but very often used in daily practice] includes ASC-US, ASC-H and/or non-classic HPV-signs; Pap IIID lesions with mild dysplasia/CINI were considered low-grade squamous intraepithelial lesions (LSIL). Pap IIID results with moderate dysplasia and Pap IVA (severe dysplasia) were classified as high-grade squamous intraepithelial lesions.

Histology. In 33 cases, histopathological diagnoses were also available either from biopsy or conisation material. CIN classification was performed using the WHO system. Histologies in lower cytological grades were not consistently available.

PCR-based HPV DNA detection and genotyping by sequencing. The HPV DNA status of all 66 cases was identified by PCR-based type-specific HPV DNA assays as previously published (15). In short, HPV DNA detection was directly performed on residual material in the ThinPrep ${ }^{\circledR}$ collection vial with PCR-based assays using the improved MY09/MY11 consensus primers and the GP5 ${ }^{+} / 6^{+}$general primers for amplification of the HPV DNA. The presence of human genomic DNA was verified by PCR amplification of the human globine gene. PCR products were purified using the High Pure PCR product purification kit (Roche Diagnostics, Mannheim, Germany). The sequence of one strand of the purified PCR fragments was determined with the BigDye Terminator sequencing kit (Applied Biosystems, Foster City, CA) using 3 pmol of $\mathrm{GP}^{+}$or MY09 as the sequencing primers. Sequencing reactions were analysed on an ABI Prism 310 automated sequencer (Applied Biosystems) and results were compared with documented virus sequences available in the GenBank database using the BLAST program (Blast, Pittsboro, NC).

HPV mRNA detection. The oncogene E6/E7 mRNA from HPV types 16, 18, 31, 33 and 45 was identified using the commercially available PreTect HPV-Proofer kit (NorChip AS) based on real-time NASBA (nucleic acid sequence based amplification) technology according to recommendations by the manufacturer. Briefly, NASBA is based on isothermal mRNA amplification, accomplished by the simultaneous enzymatic activity of avian myeloblastosis virus (AMV) reverse transcriptase, T7 RNA polymerase and RNase H. For detection we used primers and molecular beacon $(\mathrm{MB})$ probes directed against E6/E7 mRNA for HPV types 16, 18, 31, 33, 45,52 and 58. The final concentration of MBs used in the reaction was $2.5 \mathrm{mM}$. The NASBA amplification was carried out in a volume of $20 \mu \mathrm{l}$ at $41^{\circ} \mathrm{C}$ for $2.5 \mathrm{~h}$. A $5 \mu \mathrm{l}$ volume of nucleic acids, diluted five times after extraction, was included in the reaction. As a performance control, we used a primer set and probe directed against the human U1 small nuclear ribonucleoprotein (snRNP)-specific A protein (U1A mRNA) included in the kit. Negative control reactions consisting of all reagents except RNA were performed at each run.

Monitoring. The cervical status was checked 18 months after the mRNA test by repeated cytology in 60 women. For assessing cytological lesion progression versus regression, only patients with a natural disease course, i.e. without surgical therapy $(n=39)$, were considered. Cytology outcome was classified as i) regression, in cases with a decrease in the cytology grade, ii) persistent state, if the cytology remained unchanged and iii) progression, in lesions showing an advanced cytology grade. In addition, a second, type-specific 
Table I. The distribution of and correlation between the cytoand histopathological diagnoses in 33 histology-proven cases.

\begin{tabular}{lccrrr}
\hline & \multicolumn{2}{c}{ Histology } & & \\
\cline { 2 - 3 } Cytology & no CIN & CIN II & CIN III & Total \\
\hline PapIIw/ASCUS & 2 & 0 & 3 & 5 \\
Pap IIID/LSIL & 2 & 3 & 3 & 8 \\
Pap IIID, IVA/HSIL & 2 & 2 & 16 & 20 \\
Total & 6 & 5 & 22 & 33 \\
\hline
\end{tabular}

HPV DNA test was performed in 46 cases. Results were classified as i) transitory HPV infection, in cases which became HPV negative or exhibited new infections with different HPV type(s) compared to baseline, or ii) persistent, if the same genotype was detected as in the index test.

Statistical analysis. Statistical analysis was performed using the SPSS program for Windows (Version 12.0). Descriptive statistics for continuous measures are given as the mean with standard deviation (SD) and range, while frequencies and prevalences are given in row numbers and percentage. To assess the diagnostic accuracy of viral and morphological tests the following test performance parameters were calculated: sensitivity, specificity, positive (PPV) and negative predictive value (NPV) using 2x2 tables. The association between HPV DNA, RNA, histological and cytological variables was studied by $\chi^{2}$ statistics. A comparison of the prevalence of HPV E6/E7 mRNA and HPV DNA was performed by the McNemar test. For all statistics, cytological and HPV parameters were classified as being present or absent. Significance was defined at $\mathrm{P}<0.05$ and $\mathrm{P}$ was two-tailed.

\section{Results}

Cytology and histology at baseline. Sixty-six women (mean age: 34.6, range: 21-66 years) were included in this study with the following cervical cytological diagnoses: Pap II/reactive, inflammatory in 3; Pap IIw/ASCUS, in 23; Pap IIID/LSIL in 19; Pap IIID/HSIL in 11 and Pap IVa/HSIL in 10 cases. The cross-tabulation of cyto- and histopathological diagnoses in 33 informative cases is demonstrated in Table I. The chi-square statistics proved a highly significant association between the results of the two diagnostic tests (Pearson-R: 43.997, $\mathrm{P}=0.001)$.

HPV DNA at baseline. Of the 63 HPV DNA-positive cases included in the study, HPV 16 was detected in 71\% (45/63) of the cases and in 5 of the samples in association with other HPV genotypes, such as: HPV 18, 42 and 31. HPV 18 DNA was present in three, HPV 31 in seven, HPV 33 in five and HPV 45 in three cases. Multiple HPV infections were identified in 6 women $(\sim 10 \%)$. The prevalence and distribution of the 5 high-risk oncogenic HPV types investigated according to cytology is demonstrated in Table II.

HPV mRNA at baseline. HPV oncogene mRNA from types $16,18,31,33$ and 45 was detected in $58 \%(38 / 66)$ of the cases. The distribution and prevalence of HPV mRNA expression in correlation with cytology and histology is demonstrated in Table III. HPV mRNA was expressed in 9/23 ASCUS, 11/19 LSIL and 18/21 HSIL cases, whereas none of the three cases with normal/reactive (no-ASC) cytology had a positive result with the PreTect test. The association between morphology and RNA assay results was statistically, highly significant (for cytology: Pearson-R 14.34, P=0.006; for histology: Pearson-R 26.77, $\mathrm{P}=0.001)$. The diagnostic validity of the PreTect test for detecting prevalent cytological disease (HSIL) was as follows: sensitivity $87 \%(0.71-1.00,95 \% \mathrm{CI})$; specificity 56\% (0.4-0.70, 95\% CI); PPV 47\% (0.31-0.63, $95 \% \mathrm{CI})$ and NPV $89 \%(0.78-1.00,95 \% \mathrm{CI})$.

Of the 22 histologically-proven CIN 3 cases, 20 expressed HPV 16 mRNA, one was positive for HPV 45 mRNA and one sample was negative by the PreTect assay. Of the 5 CIN2 cases, 4 were negative for HPV mRNA and 1 expressed HPV 18 mRNA. Six cases were without CIN, 2 of them were RNA negative, 2 expressed HPV 16 mRNA, 1 case was positive for

Table II. The distribution and prevalence of HPV types according to cytology.

\begin{tabular}{lccccc}
\hline \multicolumn{7}{c}{ Index cytology } \\
\hline HPV DNA & $\begin{array}{c}\text { no-ASC } \\
\text { (Pap II) }\end{array}$ & $\begin{array}{c}\text { ASCUS } \\
\text { (Pap IIw) }\end{array}$ & $\begin{array}{c}\text { LSIL } \\
\text { (Pap IIID) }\end{array}$ & $\begin{array}{c}\text { HSIL } \\
\text { (Pap IIID+IVA) }\end{array}$ & Total \\
\hline 16 & 0 & 14 & 10 & 15 & 39 \\
$16+31$ & 0 & 0 & 3 & 1 & 4 \\
$16+18+42$ & 0 & 1 & 0 & 0 & 1 \\
18 & 0 & 1 & 1 & 1 & 3 \\
31 & 0 & 1 & 0 & 2 & 7 \\
$31+45$ & 0 & 1 & 3 & 0 & 5 \\
33 & 0 & 2 & 1 & 0 & 3 \\
45 & 0 & 0 & 0 & 0 & 3 \\
Negative & 3 & 23 & 19 & 21 & 66 \\
Total & 3 & & & & 1 \\
\hline
\end{tabular}


Table III. The distribution and prevalence of oncogene HPV mRNA types according to cytology ( $\mathrm{n}=66$ ) and histology ( $\mathrm{n}=33$ ).

\begin{tabular}{lccccc}
\hline & \multicolumn{3}{c}{ Cytology } \\
\hline HPV mRNA & $\begin{array}{c}\text { no-ASC } \\
\text { (Pap II) }\end{array}$ & $\begin{array}{c}\text { ASCUS } \\
\text { (Pap IIw) }\end{array}$ & $\begin{array}{c}\text { LSIL } \\
\text { (Pap IIID) }\end{array}$ & $\begin{array}{c}\text { HSIL } \\
\text { (Pap IIID+IVA) }\end{array}$ \\
\hline Negative & 3 & 14 & 8 & 3 & Total \\
16 & 0 & 7 & 6 & 15 & 28 \\
18 & 0 & 0 & 0 & 0 & 2 \\
31 & 0 & 0 & 2 & 0 & 2 \\
33 & 0 & 0 & 1 & 1 & 2 \\
45 & 0 & 1 & 0 & 0 & 3 \\
$16+45$ & 0 & 1 & 19 & 21 & 66 \\
Total & 3 & 23 & 1 & \\
\hline
\end{tabular}

Pearson-R 14.34, $\mathrm{P}=0.006$.

Histology

\begin{tabular}{lccrr}
\hline HPV mRNA & no CIN & CIN II & CIN III & Total \\
\hline Negative & 2 & 4 & 1 & 7 \\
16 & 2 & 0 & 20 & 22 \\
18 & 1 & 0 & 0 & 2 \\
31 & 1 & 0 & 0 & 1 \\
45 & 0 & 5 & 22 & 33 \\
Total & 6 & & 1 & 1 \\
\hline
\end{tabular}

Pearson-R 26.77, $\mathrm{P}=0.001$.

HPV 18 and another 1 for HPV 31. Based on these results, the diagnostic validity of the PreTect test in detecting CIN2+ lesions was: sensitivity $81 \%(0.67-0.96,95 \% \mathrm{CI})$; specificity $33 \%(-0.04-0.71,95 \% \mathrm{CI})$; PPV 85\% (0.71-0.98, 95\% CI) and NPV $29 \%(-0.05-0.6,95 \% \mathrm{CI})$.

By grouping CIN2 cases together with no-CIN histologies into the lower grade category, the sensitivity of the PreTect test for detecting prevalent CIN3 disease increased to 95\% (0.87$0.1,95 \% \mathrm{CI})$; specificity was $55 \%(0.25-0.84,95 \% \mathrm{CI})$; PPV $81 \%(0.66-0.96,95 \% \mathrm{CI})$ and NPV $86 \%(0.6-1.11,95 \% \mathrm{CI})$.

HPV DNA and mRNA at baseline. All HPV mRNA positive cases were also positive for HPV DNA $(n=38)$ with $97 \%$ concordance between the type-specific detection of the respective molecules from the two methods in double-positive cases. Of the DNA positive cases, 25 (38\%) did not express a transcribed mRNA. Three cases were negative for HPV DNA and mRNA. From a total of 6 women with multiple HPV DNA infections, E6/E7 mRNA from at least one HPV type was detected in 4 cases and 2 were negative by the PreTect test. In one sample expressing two mRNA types (HPV 16 and 45), only the presence of HPV 16 DNA was detected. There were highly significant associations between HPV genotypes and the mRNA type expressed in the samples (Pearson-R: 147.283, $\mathrm{P}=0.000)$. These associations are demonstrated in Tables IV and V. Agreement between HPV DNA and mRNA detection was statistically highly significant (McNemar, $\mathrm{P}=0.000)$.

Morphology and HPV at baseline. The frequency and distribution of type-specific HPV mRNA and DNA in association with index cytology is shown in Table VI. The global results of HPV testing related to cytology are demonstrated in Fig. 1a. Three women had a normal/reactive cytology and both HPV tests were negative in these cases. Twenty-three women had ASCUS, all samples were positive for HPV DNA and nine of them expressed HPV oncogene mRNA. In the LSIL group $(\mathrm{n}=19)$, HPV mRNA was detected in 11 and DNA in 18 cases. HSIL cases (18 out of 21) showed an HPV mRNA expression and all of them contained HPV DNA.

HPV testing results related to histology diagnoses are shown in Fig. 1b. HPV DNA positive cases (4 out of 5) without CIN expressed oncogenic HPV mRNA, whereas there was only one mRNA positive sample out of five DNA positive CIN2 lesions. Of the 22 CIN3 cases, all were positive for HPV DNA and 21 were also positive for mRNA. The one discordant case had an HPV 31 DNA and a negative mRNA result.

Follow-up. From a total of 60 patients with cytological followup results, 21 received surgical treatment (conisation) during the surveillance period of 18 months. These patients were not considered for prognostic evaluation of the mRNA assay. Of 

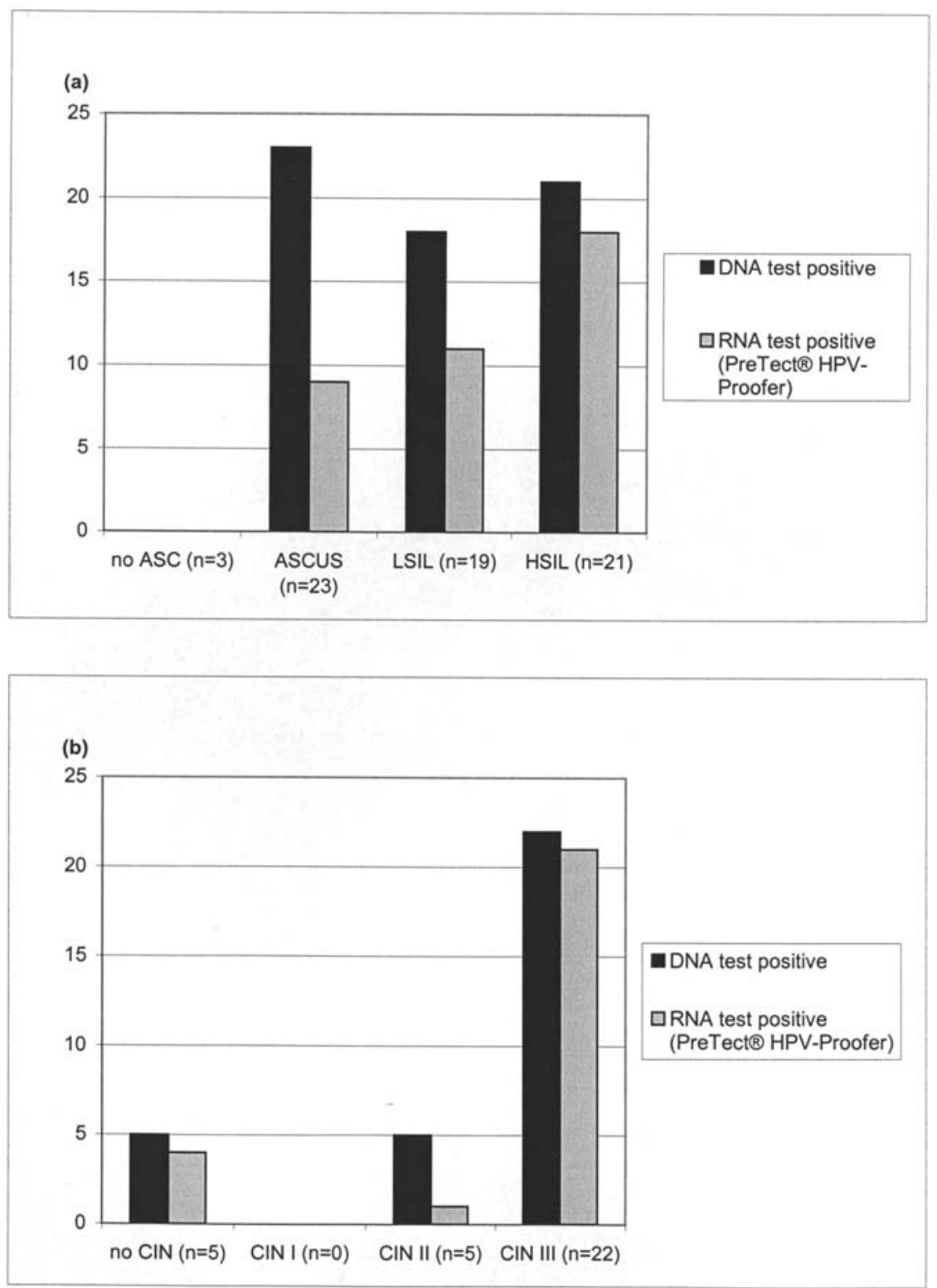

Figure 1. (a) HPV testing related to cytology $(n=66)$, (b) HPV testing related to histology $(n=33)$.

Table IV. The frequency and distribution of HPV genotypes in association with HPV oncogene mRNA expression.

\begin{tabular}{lrrrrrrrr}
\hline \multicolumn{7}{c}{ HPV mRNA } \\
\hline HPV DNA & 16 & $16+45$ & 18 & 31 & 33 & 45 & Negative & Total \\
\hline 16 & 26 & 1 & - & - & - & - & 12 & 39 \\
$16+18+42$ & - & - & - & - & - & - & 1 & 1 \\
$16+31$ & 2 & - & - & 1 & - & 1 & - & 4 \\
18 & - & - & 2 & - & - & - & 1 & 3 \\
31 & - & - & - & 1 & - & - & 6 & 7 \\
$31+51$ & - & - & - & - & - & - & 1 & 1 \\
33 & - & - & - & - & 2 & - & 3 & 5 \\
45 & - & - & - & - & - & 2 & 1 & 3 \\
Negative & 28 & 1 & 2 & 2 & 2 & 3 & 28 & 66 \\
Total & & & - & - & - & - & 3 & 3 \\
\hline
\end{tabular}


Table V. Agreement between HPV mRNA test (NorChip) and HPV DNA detection by genotyping.

\begin{tabular}{lccc}
\hline & DNA positive & DNA negative & Total \\
\hline mRNA positive & 38 & 0 & 38 \\
mRNA negative & 25 & 3 & 28 \\
Total & 63 & 3 & 66 \\
\hline
\end{tabular}

McNemar, $\mathrm{P}=0.000$.

the remaining 39 patients, who exhibited a natural course of HPV infection, 9 (23\%) experienced cytological disease progression, 9 had persistent cytology status and 21 showed cytological regression. Nineteen of the cases expressed HPV mRNA at baseline and 20 were negative as shown in Table VII. Based on these associations, the prognostic validity of the PreTect test for detecting cytological disease progression versus regression/persistence during the 18-month natural course of HPV infection in the present study were: sensitivity $77.7 \%(0.51-1.05,95 \% \mathrm{CI})$; specificity $60 \%(0.42-0.77,95 \%$ CI); PPV $37 \%(0.15-0.58,95 \% \mathrm{CI})$ and NPV $90 \%(0.77-1.03$, $95 \% \mathrm{CI}$ ).

HPV DNA follow-up data were available in 29 out of the non-treated cases with 15 cases showing type-specific virus persistence. The frequency of HPV types in persistent infections were: 7x HPV 16, 3x HPV 31, 2x HPV 18, 2x HPV 33 and 1x HPV 45.

The data of the nine patients in the non-treated group, who experienced cytological progression during the 18-month follow-up, are demonstrated in Table VIII. All were HPV DNA positive (HPV 16 5x, HPV 16+31 1x, HPV 18 1x, HPV $331 \mathrm{x}$ and HPV $451 \mathrm{x}$ ) at baseline and all had type-specific persistent HPV infection at the 18-month follow-up. Seven expressed oncogenic E6/E7 mRNA and 2 were negative with the PreTect test at baseline. Index cytology was ASCUS in 3 and LSIL in 6 cases, biopsy was performed in 4 cases with results of no-CIN in 2, with CIN2 and CIN III of 1 case each.

\section{Discussion}

In this study, the diagnostic and prognostic validity of the detection of HPV mRNA transcripts of E6/E7 oncogenes from HPV types 16, 18, 31, 33 and 45 was investigated in 66 consecutive women from a routine cervical screening setting using the PreTect HPV-Proofer assay. Baseline cytologies encompassed the complete spectrum of squamous cell abnormalities up to HSIL and contained, except for the three negative control cases, HPV DNA from at least 1 out of the 5 high-risk HPV types included in the RNA test. These HPVs are considered to be the most prevalent 'high-risk' types in Europe and North America, which are implicated in $>90 \%$ of cervical carcinomas $(16,17)$. Accordingly, the most common virus type in the present series was HPV $16(68 \%)$, regardless

Table VI. Global frequency and distribution of type-specific HPV mRNA and DNA in association with index cytology.

\begin{tabular}{|c|c|c|c|c|c|c|}
\hline \multirow[b]{2}{*}{ HPV mRNA } & \multirow[b]{2}{*}{ HPV DNA } & \multicolumn{4}{|c|}{ Index cytology } & \multirow[b]{2}{*}{ Total } \\
\hline & & $\begin{array}{l}\text { no-ASC } \\
\text { (Pap II) }\end{array}$ & $\begin{array}{l}\text { ASCUS } \\
\text { (Pap IIw) }\end{array}$ & $\begin{array}{c}\text { LSIL } \\
\text { (Pap IIID) }\end{array}$ & $\begin{array}{c}\text { HSIL } \\
\text { (PapIIID+IVA) }\end{array}$ & \\
\hline \multirow[t]{2}{*}{16} & 16 & 0 & 8 & 6 & 15 & 29 \\
\hline & $16+31$ & 0 & 0 & 2 & 0 & 2 \\
\hline $16+45$ & 16 & 0 & 1 & 0 & 0 & 1 \\
\hline 18 & 18 & 0 & 0 & 0 & 2 & 2 \\
\hline \multirow[t]{2}{*}{31} & 31 & 0 & 0 & 1 & 0 & 1 \\
\hline & $16+31$ & 0 & 0 & 1 & 0 & 1 \\
\hline 33 & 33 & 0 & 0 & 2 & 0 & 2 \\
\hline \multirow[t]{2}{*}{45} & 45 & 0 & 1 & 1 & 0 & 2 \\
\hline & $16+31$ & 0 & 0 & 0 & 1 & 1 \\
\hline \multirow[t]{8}{*}{ Negative } & 16 & 0 & 6 & 4 & 0 & 10 \\
\hline & $16+18+42$ & 0 & 1 & 0 & 0 & 1 \\
\hline & 18 & 0 & 1 & 0 & 0 & 1 \\
\hline & 31 & 0 & 3 & 1 & 2 & 6 \\
\hline & $31+51$ & 0 & 1 & 0 & 0 & 1 \\
\hline & 33 & 0 & 0 & 1 & 1 & 2 \\
\hline & 45 & 0 & 1 & 0 & 0 & 1 \\
\hline & negative & 3 & 0 & 0 & 0 & 3 \\
\hline Total & & 3 & 23 & 19 & 21 & 66 \\
\hline
\end{tabular}


Table VII. The prognostic power of the HPV mRNA (NorChip) test for detecting cytological disease progression.

\begin{tabular}{lcccc}
\hline & $\begin{array}{c}\text { Cytological disease } \\
\text { progression }\end{array}$ & $\begin{array}{c}\text { Cytological disease } \\
\text { regression }^{\mathrm{a}}\end{array}$ & $\begin{array}{c}\text { Cytological disease } \\
\text { persistence }^{\mathrm{a}}\end{array}$ & $\begin{array}{c}\text { Total } \\
\text { mRNA positive }\end{array}$ \\
mRNA negative & 7 & 11 & 1 & 19 \\
Total & 2 & 10 & 8 & 20 \\
\hline
\end{tabular}

${ }^{a}$ For statistical purposes, cytological disease progression and regression were classified into one group as opposed to disease progression. Sensitivity: $78 \%(0.50-1.05,95 \%$ CI ); specificity: $60 \%$ (0.42-0.76, $95 \%$ CI ); positive predictive value (PPV): $37 \%(0.15-0.58,95 \% \mathrm{CI})$ and negative predictive value (NPV): $90 \%(0.77-1.03,95 \% \mathrm{CI})$.

Table VIII. Global data from nine women who were not treated surgically and developed cytological disease progression during the 18-month follow-up.

\begin{tabular}{cccccccccc}
\hline $\begin{array}{c}\text { Age } \\
\text { (yrs) }\end{array}$ & $\begin{array}{c}\text { Baseline } \\
\text { HPV DNA }\end{array}$ & $\begin{array}{c}\text { HPV } \\
\text { mRNA }\end{array}$ & $\begin{array}{c}\text { Baseline } \\
\text { cytology }\end{array}$ & Surgery & Histology & $\begin{array}{c}\text { Follow-up } \\
\text { cytology }\end{array}$ & $\begin{array}{c}\text { Follow-up } \\
\text { HPV DNA }\end{array}$ & $\begin{array}{c}\text { HPV } \\
\text { dynamics }\end{array}$ \\
\hline 1 & 33 & 18 & negative & IIw/ASCUS & - & - & IIID/HSIL & $18+31$ & persistence (18) \\
2 & 30 & 16 & $16+45$ & IIw/ASCUS & - & - & IIID/LSIL & 16 & persistence (16) \\
3 & 51 & 16 & 16 & IIw/ASCUS & - & - & IIID/LSIL & 16 & persistence (16) \\
4 & 25 & 16 & negative & IIID/LSIL & biopsy & CIN II & IIID/HSIL & 16 & persistence (16) \\
5 & 28 & 16 & 16 & IIID/LSIL & biopsy & no CIN & IIID/HSIL & 16 & persistence (16) \\
6 & 52 & 33 & 33 & IIID/LSIL & - & - & IIID/HSIL & 33 & persistence (33) \\
7 & 28 & 16 & 16 & IIID/LSIL & biopsy & CIN III & IVa/HSIL & 16 & persistence (16) \\
8 & 30 & $16+31$ & $31 ?$ & IIID/LSIL & biopsy & no CIN & IVa/HSIL & 31 & persistence (31) \\
9 & 33 & 45 & 45 & IIID/LSIL & - & - & IIID/HSIL & 45 & persistence (45) \\
\hline
\end{tabular}

of the severity of the cytological diagnosis, followed by HPV 31 (13\%), HPV 33 (9\%), HPV 18 (5\%) and HPV 45 (5\%) in mono-infections.

Expression of HPV E6/E7 mRNA was detected in 58\% of the studies, similar to the findings of others $(12,13)$, and showing a $97 \%$ concordance with HPV DNA types in double positive cases. There was a statistically highly significant association between the RNA status and cytological/ histological diagnoses (Pearson's $\mathrm{P}=0.006$ and $\mathrm{P}=0.001$, respectively) and a positive correlation with an increasing cytological and histological grade (Fig. 1a and b), as published by other investigators (13). The majority of HPV DNA and RNA discrepant cases $(n=25)$ occurred in the groups with ASCUS and LSIL cytology and CIN2 histology. All discrepant cases had positive HPV DNA and negative mRNA test results.

The difference between the detection rates of HPV DNA and mRNA can partially be explained by differences in viral activity and the type of lesions induced by them. Practically, all HPV infections express E6/E7 oncogenes at a certain time interval, as they code for necessary viral proteins in the normal viral life cycle (18). During an acute productive HPV infection, a regulated expression of viral genes, particularly E6 and E7 oncogenes is restricted to differentiated epithelial cells, which lost the ability to replicate their genomes. In latent and abortive HPV infections, as well as in low-grade intra- epithelial neoplasias, these cells are located in the basal and parabasal cell layers, which may not be present in superficial exfoliative cytology samples (sampling error). This may explain the presence of HPV DNA without a detectable oncogene E6/E7 mRNA expression in lower grade lesions. In contrast, high-grade cervical lesions represent abortive papillomavirus infections in which the life-cycle of the virus is altered (19). This is demonstrated by an increased expression of E6 and E7 oncogenes throughout the entire thickness of the epithelium (20). Therefore, the detection of E6 and E7 mRNA in exfoliated cervical epithelial cells rather reflects a high grade-lesion more likely to persist or progress.

Nevertheless, the mRNA test in the present study was negative in $19 \%$ of histologically-proven CIN2 and CIN3, resulting in $81 \%$ sensitivity for detecting prevalent CIN2 ${ }^{+}$ lesions. Similar observations were also made by others $(12,21)$. However, it is well known that the use of the CIN2 category is controversial, due to the poor reproducibility of diagnosis among pathologists (22). Therefore, we increased the sensitivity of the PreTect test up to $95 \%$ if the endpoint was set at CIN3. Furthermore, our results showed that the pattern of HPV genotypes and mRNA status in CIN2 more closely resembled that of LSIL and no-CIN than HSIL and CIN3 (Tables III, VI and Fig. 1a and b). This is also supported by follow-up and molecular biology studies that placed CIN2 nearer to CIN1 than CIN3 with respect to its likelihood of 
progressing into invasive cancer $(23,24)$. Therefore, CIN3+ may be a more relevant endpoint for assessing the accuracy of triage methods than CIN2+.

In contrast, 4 out of the 5 women with no-CIN histology had positive results with the mRNA test (2x HPV 16, 1x HPV 18 and 1x HPV 31). Since no conisation was performed in these women, we do not know whether higher grade CINs were located beyond the area of the biopsy. The follow-up showed a cytological disease progression in 2 of the patients. As the PreTect HPV-Proofer assay detects full-length E6/E7 mRNA, a positive result should correlate with the presence of an integrated HPV, loss of HPV replication and a stabilised E6/E7 mRNA expression even in cases with negative histologies or low-grade cytologies (25). These women are at an increased risk for SIL progression (26).

Another possible use of the detection of the oncogenic mRNA expression is the unravelling of cases with multiple HPV infections. In the present study, $>1$ HPV DNA type was present in $10 \%$ of the women, the majority of whom had ASCUS and LSIL cytologies and two cases occurred in individuals with CIN3 histology. In all multiple DNA positive samples only one mRNA type was transcribed, supporting the notion that pathogenic HPV-associated effects are conferred by one dominant type within a multiple infection, with the rest representing a commensal population (21). Out of the 39 women who did not receive conisation, nine (23\%) experienced cytological disease progression during the 18month follow-up. All of them had type-specific persistent infection, seven were positive for E6/E7 mRNA at baseline, whereas two women had a negative mRNA test result. A possible explanation for the latter cases is that these lesions represent HPV infections either with non-integrated viral DNA, or HPV infections with low-transcriptional activity producing mRNA below the detection threshold of the test. Regarding HPV DNA integration, evidence is accumulating to show that oncogenic mRNA can be transcribed from episomal and integrated HPV DNAs indicating that HPV integration is not crucial for carcinoma progression (27).

Our results suggest that SILs (cytology) and $\leq$ CIN2 (histology) represent a heterogeneous group of HPV-related cervical lesions in terms of biological potential. As the HPV genotype and mRNA expression are objective parameters, the combined approach of a two-tier cytologic interpretation (according to the Bethesda system) and HPV genotyping with oncogenic mRNA detection may help in identifying women with a prevalent CIN3, with a sensitivity near $100 \%$ in the present study, and who are at high risk for progression to invasive carcinoma. For women with a negative mRNA result and cytologies up to LSIL, a negative predictive value of $90 \%$ for disease progression can be achieved by the PreTect test implying that the surveillance periods for these women can be safely lengthened. In addition, the positive predictive value (PPV) of the prediction of disease progression was $37 \%$ in our study. This is an improvement of $21 \%$ compared with accepted PPVs for progression to CIN3 and invasive cancer by CIN grade - the current 'gold standard' alone [ $10 \%$ for CIN1 and $20 \%$ for CIN2, $16 \%$ on average $(23,28)]$. Similar increases in PPVs for progression have been observed on using certain proliferation, differentiation and other HPV-associated biomarkers, such as Ki67, cytokeratins
$14 / 13$, retinoblastoma protein $(29,30)$ and DNA aneuploidy (31), indicating that molecular biomarkers are potentially important determinators of early CIN behaviour. It should be noted that a $1 \%$ increase of the PPV may prevent overtreatment in $>1000$ women annually in the European Union alone with a considerable socio-economic impact (30).

In conclusion, the detection of oncogenic E6/E7 mRNA transcripts by the PreTect HPV-Proofer has a high specificity for detecting prevalent CIN3 cases and improves the selection of women at increased risk for disease progression with HPV-induced squamous cell abnormalities. Larger scale clinical studies are needed to prove our preliminary results.

\section{Acknowledgements}

We would like to thank Marianna Szendy and Ante Trosic for the excellent technical assistance and cytology screening. The manuscript contains parts of the doctoral thesis of Christiane Klozoris.

\section{References}

1. Schiffman MH, Bauer HM, Hoover RN, et al: Epidemiologic evidence showing that human papillomavirus infection causes most cervical intraepithelial neoplasia. J Natl Cancer Inst 85: 958-964, 1993.

2. Bosch FX, Manos MM, Munoz N, et al: Prevalence of human papillomavirus in cervical cancer: a worldwide perspective. International biological study on cervical cancer (IBSCC) study group. J Natl Cancer Inst 87: 796-802, 1995.

3. Walboomers JMM, Jacobs MV, Manos MM, et al: Human papillomavirus is a necessary cause of invasive cervical cancer worldwide. J Pathol 189: 1-3, 1999.

4. Lytwin A, Sellors JW, Mahony JB, et al: Adjunctive human papillomavirus testing in the 2-year follow-up of women with low-grade cervical cytologic abnormalities: a randomized trial and economic evaluation. Arch Pathol Lab Med 127: 1169-1175, 2003.

5. Ho GY, Bierman R, Beardsley L, Chang CJ and Burk RD: Natural history of cervicovaginal papillomavirus infection in young women. N Engl J Med 338: 423-428, 1998.

6. Moscicki AB, Shiboski S, Hills NK, Powell KJ, Jay N, Hanson EN, et al: Regression of low-grade squamous intraepithelial lesions in young women. Lancet 364: 1678-1683, 2004.

7. Ho GY, Burk RD, Klein S, Kadish AS, Chang CJ, Palan P, et al: Persistent genital human papillomavirus infection as a risk factor for persistent cervical dysplasia. J Natl Cancer Inst 87: 1365-1371, 1995.

8. Kjaer SK, van den Brule AJ, Paul G, et al: Type-specific persistence of high-risk human papillomavirus (HPV) as indicator of high-grade cervical squamous intraepithelial lesions in young women: population based prospective follow-up study. BMJ 325: 1-7, 2002.

9. Watanabe S, Kanda T and Yoshiike K: Human papillomavirus type 16 transformation of primary human embryonic fibroblasts requires expression of open reading frames E6 and E7. J Virol 63: $965-969,1989$.

10. Hudson JB, Bedell MA, McCane DJ and Laiminis LA: Immortalization and altered differentiation of human keratinocytes in vitro by the E6 and E7 open reading frames of human papillomavirus type 18. J Virol 64: 519-526, 1990.

11. Sotlar K, Selinka HC, Menton M, Kandolf R and Bultmann B: Detection of human papillomavirus type $16 \mathrm{E} 6 / \mathrm{E} 7$ oncogene transcripts in dysplastic and non-dysplastic cervical scrapes by nested RT-PCR. Gynecol Oncol 69: 114-121, 1998.

12. Lie AK, Risberg B, Borge B, et al: DNA- versus RNA-based methods for human papillomavirus detection in cervical neoplasia. Gynecol Oncol 97: 908-915, 2005.

13. Molden T, Kraus I, Karlsen F, Skomedal H and Hagmar B: Human papillomavirus E6/E7 mRNA expression in women younger than 30 years of age. Gynecol Oncol 100: 95-100, 2006 . 
14. Soost HJ: Befundwiedergabe in der gynäkologischen Zytodiagnostik -Münchener Normenklatur II. Gynäkol Prax 14: 433-438, 1990.

15. Speich N, Schmitt C, Bollmann R and Bollmann M: Human papillomavirus (HPV) study of 2916 cytological samples by PCR and DNA sequencing: genotype spectrum of patients from the West German area. J Med Microbiol 53: 125-128, 2004.

16. Munoz N, Bosch FX, Sanjose S, et al: Epidemiologic classification of human papillomavirus types associated with cervical cancer. N Engl J Med 348: 518-527, 2003.

17. Clifford GM, Smith JS, Plummer M, Munoz N and Franceschi S: Human papillomavirus types in invasive cervical cancer worldwide: a meta-analysis. Br J Cancer 88: 63-73, 2003.

18. Stanley MA: Human papillomavirus and cervical carcinogenesis. Best Pract Res Clin Obstet Gynaecol 15: 663-676, 2001.

19. Middleton K, Peh W, Southern SA, et al: Organisation of the human papillomavirus productive cell cycle during neoplastic progression provides a basis for the selection of diagnostic markers. J Virol 77: 10186-10201, 2003.

20. Snijders PJF, Steenbergen RDM, Heideman DAM and Meijer CJLM: HPV-mediated cervical carcinogenesis: concepts and clinical implications. J Pathol 208: 152-164, 2006.

21. Cuschieri KS, Whitley MJ and Cubie HA: Human papillomavirus type-specific DNA and RNA persistence - Implications for cervical disease progression and monitoring. J Med Virol 73: 65-70, 2004.

22. Stoler MH and Schiffman M: Interobserver reproducibility of cervical cytologic and histologic interpretations: Realistic estimates from the ASCUS-LSIL triage study. JAMA 285: 1500-1505, 2001

23. Ostor AG: Natural history of cervical intraepithelial neoplasia: a critical review. Int J Gynecol Pathol 12: 186-192, 1993.
24. Mitchell MF, Tortolero-Luna G, Wright T, et al: Cervical human papillomavirus infection and intraepithelial neoplasia: a review. J Natl Cancer Inst Monogr 21: 17-25, 1996.

25. Andersson S, Hansson B, Norman I, et al: Expression of E6/E7 mRNA from 'high-risk' human papillomavirus in relation to CIN grade, viral load and p16INK4a. Int J Oncol 29: 705-711, 2006.

26. Molden T, Nygard JF, Kraus I, et al: Predicting CIN2+ when detecting HPV mRNA and DNA by PreTect HPV-Proofer and consensus PCR: a 2-year follow-up of women with ASCUS or LSIL Pap smears. Int J Cancer 114: 973-976, 2005.

27. Kisseljov FL, Kisseljova NP, Kobzeva VK, et al: State of human papillomavirus DNA in cervical carcinomas. Mol Biol 35: 399-404, 2001

28. Kiviat NB: Natural history of cervical neoplasia: overview and update. Am J Obstet Gynecol 175: 1099-1104, 1996.

29. Kruse AJ, Skaland I, Janssen EA, Buhr-Wildhagen S, Klos J, Arends MJ and Baak JP: Quantitative molecular parameters to identify low-risk and high-risk early CIN lesions: role of markers of proliferative activity and differentiation and $\mathrm{Rb}$ availability. Int J Gynecol Pathol 23: 100-109, 2004.

30. Baak JPA, Kruse AJ, Janssen E and van Diermen B: Predictive testing of early CIN behaviour by molecular biomarkers. Cell Oncol 27: 277-280, 2005.

31. Bollmann R, Mehes G, Torka R, Speich N, Schmitt C and Bollmann M: Determination of features indicating progression in atypical squamous cells with undetermined significance: human papillomavirus typing and DNA ploidy analysis from liquid-based cytologic samples. Cancer (Cancer Cytopathol) 99: 113-117, 2003. 